\title{
Clinical significance of serum soluble death receptor 5 concentration in locally advanced non-small cell lung cancer patients
}

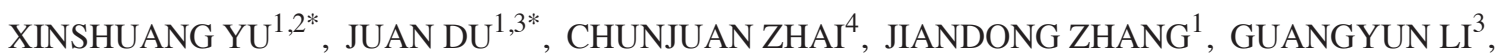 \\ WEI DONG ${ }^{2}$, DEGUO XU ${ }^{1}$, FENGJUN LIU $^{1}$, ZHEN LIU $^{1}$, YUAN TIAN ${ }^{1}$, \\ MEIJUAN SONG ${ }^{1}$, YING JU ${ }^{5}$ and BAOSHENG $\mathrm{LI}^{2}$
}

\footnotetext{
${ }^{1}$ Department of Radiation Oncology, Shandong Provincial Qianfoshan Hospital, Shandong University, Shandong 250014;

${ }^{2}$ Sixth Department of Radiation Oncology, Shandong Cancer Hospital, Jinan, Shandong 250117; ${ }^{3}$ Central Laboratory, Shandong Provincial Qianfoshan Hospital, Shandong University, Shandong 250014; Departments of

${ }^{4}$ Cardiology and ${ }^{5}$ Clinical Laboratory, Shandong Provincial Hospital Affiliated to Shandong University, Shandong University, Jinan, Shandong 250014, P.R. China
}

Received November 16, 2013; Accepted May 23, 2014

DOI: $10.3892 / 01.2014 .2237$

\begin{abstract}
There is an urgent requirement for the identification of suitable biomarkers for the diagnosis and prognosis of non-small cell lung cancer (NSCLC). The present study aimed to measure the levels of serum soluble death receptor 5 (sDR5) in patients with locally advanced stage III NSCLC, and to evaluate its diagnostic and prognostic significance in these patients. The sDR5 concentrations were evaluated by the enzyme-linked immunosorbent assay method in 50 healthy controls and 122 patients with locally advanced stage III NSCLC [including 57 adenocarcinoma (ADC) and 65 squamous cell carcinoma (SCC) patients], before and after concurrent chemoradiotherapy. It was found that the pretreatment SDR5 levels in patients with NSCLC were higher than the sDR5 levels of healthy controls $(\mathrm{P}<0.001)$. However, no significant difference in the sDR5 levels was observed between the ADC and SCC subgroups ( $\mathrm{P}=0.874)$. According to multiple clinical classifications, a significant increase in the pretreatment serum sDR5 levels could be observed in IIIB-stage patients compared with IIIA-stage patients $(\mathrm{P}=0.009)$. Patients with a tumor burden $>3 \mathrm{~cm}$ had higher pretreatment sDR5 concentration than those with a tumor burden $\leq 3 \mathrm{~cm}(\mathrm{P}=0.026)$. Additionally, T4-stage patients had significantly higher pretreatment sDR5 levels compared with those of $\mathrm{T} 1$-stage patients $(\mathrm{P}<0.001)$. There were no significant differences between pre- and post-treatment sDR5
\end{abstract}

Correspondence to: Dr Baosheng Li, Sixth Department of Radiation Oncology, Shandong Cancer Hospital, 440 Jiyan Road, Jinan, Shandong 250117, P.R. China

E-mail: baoshli@yahoo.com

*Contributed equally

Key words: soluble death receptor 5, non-small cell lung cancer, chemoradiotherapy concentrations in the total NSCLC patient group ( $\mathrm{P}=0.462)$, ADC subgroup $(\mathrm{P}=0.066)$ and $\mathrm{SCC}$ subgroup $(\mathrm{P}=0.052)$. Furthermore, when patients were divided according to therapeutic response, the pretreatment sDR5 levels in the responder patients were significantly lower compared with those of the non-responders $(\mathrm{P}<0.001)$. Further survival analysis showed that the patients whose pretreatment sDR5 levels were $\leq 14 \mathrm{pg} / \mathrm{ml}$ (cutoff value, $14 \mathrm{pg} / \mathrm{ml}$ ) had a longer progression-free survival (PFS) time than patients with sDR5 levels $>14 \mathrm{pg} / \mathrm{ml}$. However, no correlation was observed between the post-treatment sDR5 levels and therapeutic response or PFS time. To the best of our knowledge, the present study results provide the first evidence that the pretreatment serum levels of sDR5 may be a useful biomarker for the diagnosis, prediction and prognosis of patients with locally advanced stage III NSCLC.

\section{Introduction}

Lung cancer is one of the leading causes of cancer-related mortality worldwide, due to its late diagnosis (1), and non-small cell lung cancer (NSCLC) accounts for $>85 \%$ of all lung cancer cases (2). The majority of patients present with the advanced stage, by which time treatment is not able to cure the disease (3). Concurrent chemotherapy plus thoracic radiotherapy have become the standard therapeutic regimens for locally advanced NSCLC $(4,5)$. However, numerous patients demonstrate a poor, or occasionally, no response to these therapies, with prompt progression of the disease. Serum biomarkers are increasingly being evaluated for their ability to facilitate early diagnosis and predict therapeutic response, which may aid in the development of patient-tailored treatment strategies for NSCLC.

Apoptosis serves as a natural barrier to cancer development. Accumulated data (6) demonstrate that alterations in the expression of death ligands and their receptors are associated with carcinogenesis. FAS/FASL (CD95/CD95 ligand) and tumor necrosis factor (TNF)-related apoptosis-inducing 
Table I. Clinical characteristics of patients.

\begin{tabular}{|c|c|c|}
\hline Characteristics & $\mathrm{n}(\%)$ & sDR5 (pg/ml) \\
\hline Controls & 50 & $10.89 \pm 6.72$ \\
\hline Age, years & $48(35-70)^{\mathrm{a}}$ & \\
\hline \multicolumn{3}{|l|}{ Gender } \\
\hline Male & $25(50.0)$ & $10.83 \pm 6.98$ \\
\hline Female & $25(50.0)$ & $10.96 \pm 6.58$ \\
\hline Patients & 122 & $13.72 \pm 3.61$ \\
\hline Age, years & $51(36-68)^{a}$ & \\
\hline \multicolumn{3}{|l|}{ Gender } \\
\hline Male & $63(51.4)$ & $13.70 \pm 4.62$ \\
\hline Female & $59(48.6)$ & $13.73 \pm 4.46$ \\
\hline \multicolumn{3}{|l|}{ Histopathological type } \\
\hline Adenocarcinoma & $57(40.1)$ & $13.67 \pm 3.89$ \\
\hline Squamousl carcinoma & $65(45.8)$ & $13.77 \pm 3.32$ \\
\hline \multicolumn{3}{|l|}{ Stage } \\
\hline IIIA & $75(61.5)$ & $12.94 \pm 2.95$ \\
\hline IIIB & $47(38.5)$ & $14.62 \pm 4.03$ \\
\hline \multicolumn{3}{|l|}{ T level } \\
\hline $\mathrm{T} 1$ & $22(15.5)$ & - \\
\hline $\mathrm{T} 2$ & $37(26.1)$ & - \\
\hline $\mathrm{T} 3$ & $42(29.6)$ & - \\
\hline $\mathrm{T} 4$ & $21(14.8)$ & - \\
\hline \multicolumn{3}{|l|}{ N level } \\
\hline N0 & $7(5.70)$ & - \\
\hline N1 & $37(30.3)$ & - \\
\hline $\mathrm{N} 2$ & $43(35.2)$ & - \\
\hline N3 & $35(28.8)$ & - \\
\hline \multicolumn{3}{|l|}{ Tumor burden, cm } \\
\hline$\leq 3$ & $57(47.8)$ & $12.43 \pm 0.48$ \\
\hline$>3$ & $65(52.2)$ & $13.95 \pm 0.47$ \\
\hline \multicolumn{3}{|l|}{ Evaluation } \\
\hline Total response (rate) & $74(60.6)$ & - \\
\hline \multicolumn{3}{|l|}{ Adenocarcinoma } \\
\hline $\mathrm{CR}+\mathrm{PR}$ & $35(61.4)$ & $12.67 \pm 3.58$ \\
\hline $\mathrm{PD}+\mathrm{SD}$ & $22(38.6)$ & $15.24 \pm 3.93$ \\
\hline \multicolumn{3}{|l|}{ Squamous carcinoma } \\
\hline $\mathrm{CR}+\mathrm{PR}$ & $39(60.0)$ & $12.95 \pm 3.12$ \\
\hline $\mathrm{SD}+\mathrm{PD}$ & $26(40.0)$ & $15.00 \pm 3.28$ \\
\hline
\end{tabular}

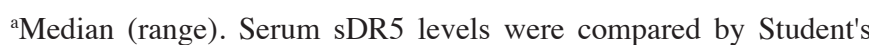
$\mathrm{t}$-test or analysis of variance. Results are shown as the means $\pm \mathrm{SD}$. Stage IIIA represents T1-2N2M0, T3N1-2M0 and T4N0-1; and stage IIIB represents T4N2M0 and T3-4N3M0, T stage and $\mathrm{N}$ stage are defined according to the seventh edition of the tumor-node-metastasis classification for malignant tumors (16). CR, complete response; $\mathrm{PR}$, partial response; $\mathrm{PD}$, progressive disease; $\mathrm{SD}$, stable disease.

ligand (TRAIL)/TRAIL receptor (TRAIL-R) are two of the important death receptor-ligand systems that have been demonstrated to be involved in processes of various human tumors (7-10). The TRAIL/TRAIL-R system has been shown
A
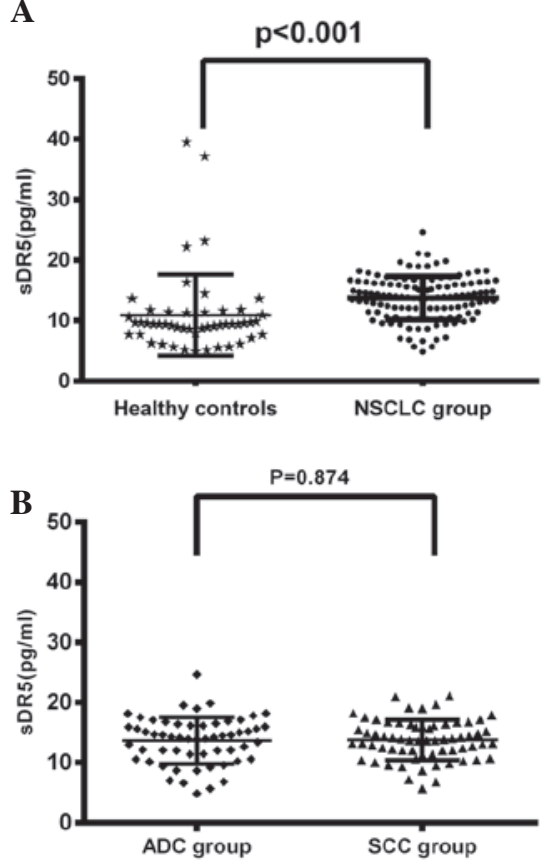

Figure 1. Detection of pretreatment sDR5 levels by enzyme-linked immunosorbent assay in 50 healthy controls and 122 NSCLC patients (including 57 ADC and 65 SCC patients). The groups were analyzed by Student's t-test. (A) Pretreatment serum sDR5 levels in NSCLC patients differed from the sDR5 levels of healthy controls $(\mathrm{P}<0.001)$. (B) No difference in pretreatment serum sDR5 levels was identified between the ADC and SCC subgroups $(\mathrm{P}=0.874)$. sDR5, soluble death receptor 5; NSCLC, non-small cell lung cancer; ADC, adenocarcinoma; SCC, squamous cell carcinoma.

to selectively induce apoptosis in various tumor cells but not in normal cells. Due to this unique merit, there is a growing interest in studying the significance of the TRAIL/TRAIL-R system in various types of cancer (11).

TRAIL has five receptors which have been identified, including two death receptors (DR4 and DR5), two decoy receptors (DcR1and DcR2) and soluble receptor osteoprotegerin (12). The binding of TRAIL to its transmembrane receptors DR4 and DR5 can activate the downstream caspase cascade and finally induce the development of apoptosis (13). DR5 has been demonstrated to possess the highest affinity with TRAIL and play the most important role in TRAIL-inducing apoptosis (14). Our previous data (15) showed that sDR5 levels played a vital role in hepatitis B virus (HBV)-induced liver damage, and serum sDR5 levels may be a useful prognostic indicator of $\mathrm{HBV}$ infection. However, the significance of serum sDR5 levels in NSCLC patients has not yet been elucidated. In the present study, we investigated serum sDR5 concentrations in patients with locally advanced stage III NSCLC, and analyzed the correlation with clinical parameters, such as histopathological type, stage of disease, tumor burden and progression-free survival (PFS). Therefore, the present study aimed to evaluate its predictive and prognostic significance in patients with locally advanced stage III NSCLC.

\section{Materials and methods}

Patients. In total, 122 patients with locally irresectable stage III NSCLC, including 57 adenocarcinoma (ADC) patients and 
A

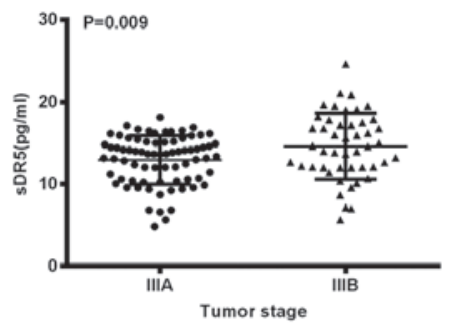

D

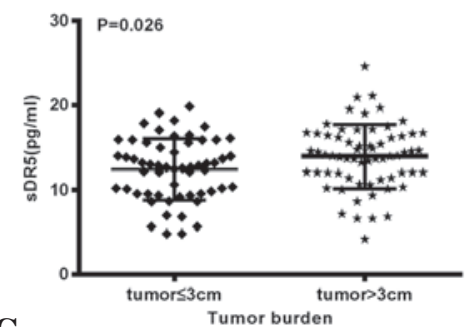

G

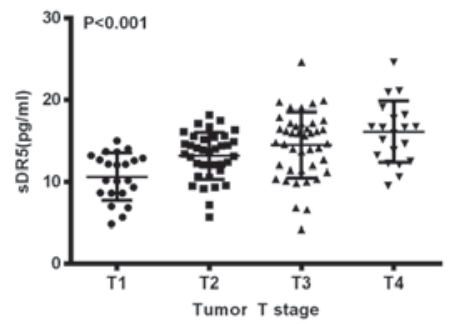

$\mathbf{J}$

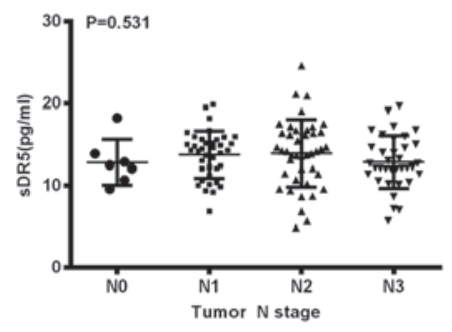

B

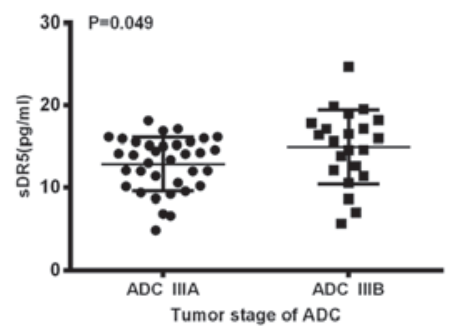

$\mathbf{E}$

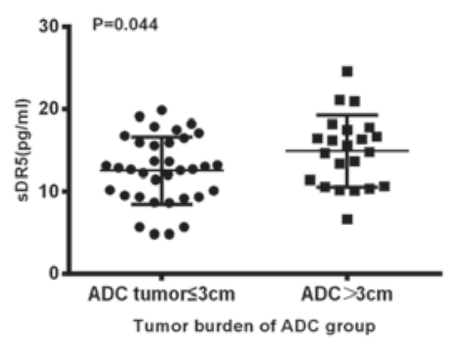

H

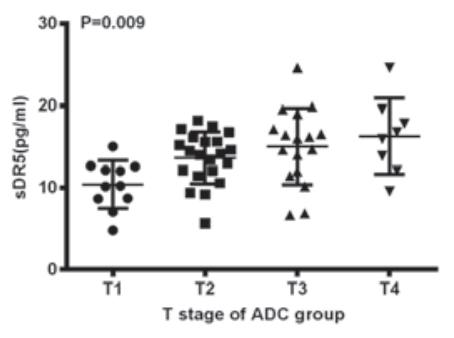

K

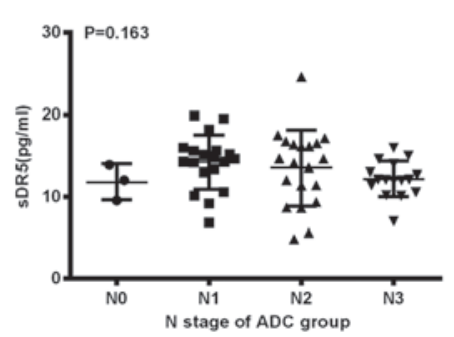

C

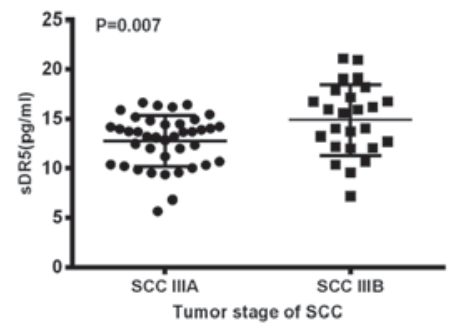

F
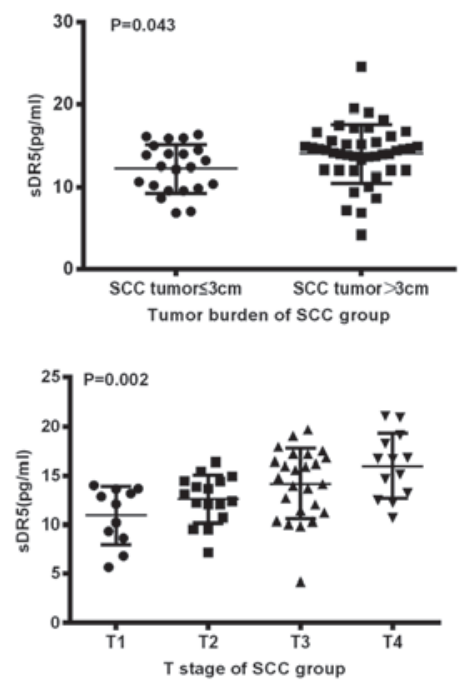

L

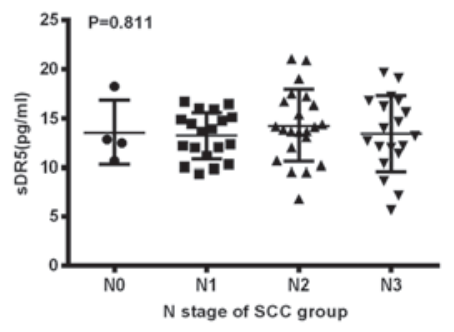

Figure 2. Correlation between pretreatment serum sDR5 levels and clinical characteristics of NSCLC patients. Pretreatment sDR5 levels were compared between IIIA and IIIB stage in (A) all NSCLC patients ( $\mathrm{P}=0.009)$, (B) the ADC subgroup ( $\mathrm{P}=0.049)$ and $(\mathrm{C})$ the SCC subgroup $(\mathrm{P}=0.007)$. Similarly, serum sDR5 levels were compared between patients with a tumor load of $\leq 3$ and $>3 \mathrm{~cm}$ in (D) all NSCLC patients $(\mathrm{P}=0.026)$, (E) the ADC subgroup ( $\mathrm{P}=0.044)$ and $(\mathrm{F})$ the SCC subgroup $(\mathrm{P}=0.043)$. Serum sDR5 levels were compared among the various T stages in $(\mathrm{G})$ all NSCLC patients $(\mathrm{P}<0.001)$, (H) the ADC subgroup $(\mathrm{P}=0.009)$ and $(\mathrm{I})$ the $\mathrm{SCC}$ subgroup $(\mathrm{P}=0.002)$. Serum sDR5 levels were compared among $\mathrm{N}$ stages in $(\mathrm{J})$ all NSCLC patients $(\mathrm{P}=0.531)$, $(\mathrm{K})$ the ADC subgroup $(\mathrm{P}=0.163)$ and $(\mathrm{L})$ the and $\mathrm{SCC}$ subgroup $(\mathrm{P}=0.811)$. The unpaired $\mathrm{t}$-test was used for analyzing the difference between two groups. Differences between multiple groups were determined by analysis of variance or the Kruskal-Wallis test. sDR5, soluble death receptor 5; NSCLC, non-small cell lung cancer; ADC, adenocarcinoma; SCC, squamous cell carcinoma.

65 squamous cell carcinoma (SCC) patients, who visited Shandong Provincial Qianfoshan Hospital (Jinan, China) between January 2010 and July 2011, were selected as candidates. All patients were histologically or cytologically confirmed. Any patient who received surgery for lung cancer was not eligible to participate. Case samples were collected at two time points: Before treatment and after concurrent chemoradiotherapy (CRT). The control group consisted of 50 healthy volunteers. All of the healthy controls were age and gender-matched with the patients. All patients were staged according to the seventh edition of the American Joint Committee on Cancer (AJCC) system for lung cancer (16). TNM (tumor nodes metastasis) staging method was used (17). Tumor response was measured using the Response Evaluation Criteria In Solid Tumors (RECIST) criteria (18).
Patients were treated with 60-Gy radiotherapy administered as $2 \mathrm{~Gy} /$ day for 5 days a week over $\sim 6$ weeks with platinum-doublet chemotherapy. The therapeutic dose was adjusted according to individual conditions. Follow-up was performed from the start of CRT to last confirmation of regression, including physical examination, blood chemistry, ultrasound of the abdomen and lymph node X-ray of the chest or CT scanning, scintigraphy of the skeleton and brain CT scanning if necessary.

This study was approved by the ethics committee of Shandong Provincial Qianfoshan Hospital. Written informed consent was provided by all patients and controls before sample collection. All serum samples were stored at $-80^{\circ} \mathrm{C}$ until batch analysis by enzyme-linked immunosorbent assay (ELISA). 
Method. The concentration of sDR5 was detected by using a solid phase sandwich ELISA kit (cat. no. IB-17792; Human DR5 ELISA kit; Shanghai Jianglai Biotech, Shanghai, China) according to the manufacturer's instructions, with the detection range from 2 to $70 \mathrm{pg} / \mathrm{ml}$. The value of absorbance at $450 \mathrm{~nm}$ was utilized to draw the standard curve and the levels of sDR5 were obtained from the curve. Each serum sample was tested in duplicate.

Statistical analysis. Serum sDR5 concentration was expressed as the mean \pm standard deviation. Differences between the two groups were analyzed by Student's t-test. Differences between multiple groups were determined by analysis of variance or the Kruskal-Wallis test. Survival analysis and curves were established according to the Kaplan-Meier method and were compared using the log-rank test. PFS was calculated as the time between the start date of the primary treatment and the date of disease progression or the last follow-up appointment. The cutoff point was chosen according to the receiver operating characteristic (ROC) analysis. Differences were considered to be statistically significant with $\mathrm{P}<0.05$. All data were analyzed using SPSS 13.0 software (SPSS, Inc., Chicago, IL, USA).

\section{Results}

Patient characteristics. The basic characteristics of the patients are shown in Table I. The median age of healthy controls was 48 years (range, 35-70 years) and that of NSCLC patients was 51 years (range, 36-68 years). No statistical difference was observed in gender or age between the controls and patients. The objective response rate, referring to complete responses (CRs) and partial responses (PRs), was 74\%. Similarly, the objective response rate in the ADC subgroup was $61.4 \%$ (35 out of 57 patients) and in SCC subgroup was $60.0 \%$ (39 out of 65 patients), respectively.

Detection of serum soluble DR5 levels in NSCLC patients and healthy controls. The pretreatment serum sDR5 levels in the healthy control group and the NSCLC group were $10.89 \pm 6.72$ and $13.72 \pm 3.61 \mathrm{pg} / \mathrm{ml}$, respectively. As presented in Fig. 1A, the pretreatment serum sDR5 levels in all patients were significantly increased compared with the sDR5 levels of healthy controls $(\mathrm{P}<0.001)$. However, the sDR5 levels showed no significant difference between the ADC and SCC patient groups (13.67 \pm 3.89 vs. $13.77 \pm 3.32$ pg/ml; $\mathrm{P}=0.874$; Fig. $1 \mathrm{~B})$.

Expression of SDR5 in association with the clinical characteristics of NSCLC patients. When the clinical classifications of the NSCLC patients were considered, a significant increase in pretreatment serum sDR5 levels could be observed in IIIB stage patients compared with IIIA stage patients ( $\mathrm{P}=0.009$; Fig. 2A). Similar results were observed between the IIIA and IIIB stage patients when patients were separated into ADC $(\mathrm{P}=0.049$; Fig. 2B) and SCC ( $\mathrm{P}=0.007$; Fig. 2C) subgroups. Regarding the tumor burden, analysis revealed a marked increase in pretreatment sDR5 concentration in patients with a tumor load of $\leq 3 \mathrm{~cm}$ compared with patients with a load of $>3 \mathrm{~cm}$ $(12.43 \pm 0.48$ vs. $13.95 \pm 0.47 \mathrm{pg} / \mathrm{ml} ; \mathrm{P}=0.026$; Fig. $2 \mathrm{D})$. Similar results were identified between the patients with different
Table II. Comparasion of sDR5 level (pg/ml) before and after chemoradiotherapy.

\begin{tabular}{lccc}
\hline & NSCLC & ADC group & SCC group \\
\hline Pre-CRT & $13.72 \pm 3.61$ & $13.73 \pm 3.88$ & $13.82 \pm 3.33$ \\
Post-CRT & $13.39 \pm 3.39$ & $13.32 \pm 3.73$ & $13.46 \pm 3.08$ \\
P-value & 0.462 & 0.066 & 0.052 \\
\hline
\end{tabular}

The paired t-test was used for analyzing the differences between patients before and after treatment. There was no statistical difference in SDR5 level before and after treatment in all NSCLC patients $(\mathrm{P}=0.462)$, the ADC group $(\mathrm{P}=0.066)$ and the $\mathrm{SCC}$ group $(\mathrm{P}=0.052)$. sDR5, soluble death receptor 5; NSCLC, non-small cell lung cancer; ADC, adenocarcinoma; SCC, squamous cell carcinoma; CRT, chemoradiotherapy.

Table III. Pretreatment sDR5 level (pg/ml) according to treatment response.

\begin{tabular}{lccc}
\hline & NSCLC & ADC group & SCC group \\
\hline Responders & $12.57 \pm 0.37$ & $12.67 \pm 3.58$ & $12.95 \pm 3.12$ \\
Non-responders & $15.16 \pm 0.49$ & $15.24 \pm 3.93$ & $15.00 \pm 3.28$ \\
P-value & $<0.0001$ & 0.014 & 0.011
\end{tabular}

Student's t-test was used for analyzing the differences in pretreatment sDR5 level according to treatment response. There was a significant difference in the sDR5 levels between the responders and non-responders in NSCLC patients $(\mathrm{P}<0.0001)$. The same trend was observed in the ADC and SCC subgroups $(\mathrm{P}=0.014$ and $\mathrm{P}=0.011$, respectively). Responders include patients with a complete or partial response, and non-responder refers to patients with stable or progressive disease. sDR5, soluble death receptor 5; NSCLC, non-small cell lung cancer; ADC, adenocarcinoma; SCC, squamous cell carcinoma.

Table IV. Post-treatment sDR5 levels (pg/ml) according to treatment response.

\begin{tabular}{lccc}
\hline & NSCLC & ADC group & SCC group \\
\hline Responders & $12.97 \pm 0.32$ & $12.93 \pm 0.48$ & $13.01 \pm 0.45$ \\
Non-responders & $14.02 \pm 0.43$ & $13.88 \pm 0.75$ & $14.13 \pm 0.51$ \\
P-value & 0.054 & 0.269 & 0.108 \\
\hline
\end{tabular}

Student's t-test was used for analyzing the differences in SDR5 levels following CRT according to treatment response. No significant difference in post-treatment sDR5 levels was identified between the responders and non-responders, in any group. Responders include patients with a complete or partial response, and non-responder refers to patients with stable or progressive disease. sDR5, soluble death receptor 5; NSCLC, non-small cell lung cancer; ADC, adenocarcinoma; SCC, squamous cell carcinoma.

tumor burdens in the ADC subgroup ( $\mathrm{P}=0.044$; Fig. 2E) and SCC ( $\mathrm{P}=0.043$; Fig. 2F) subgroups. Pretreatment serum sDR5 levels in patients with T4 stage tumors were significantly 

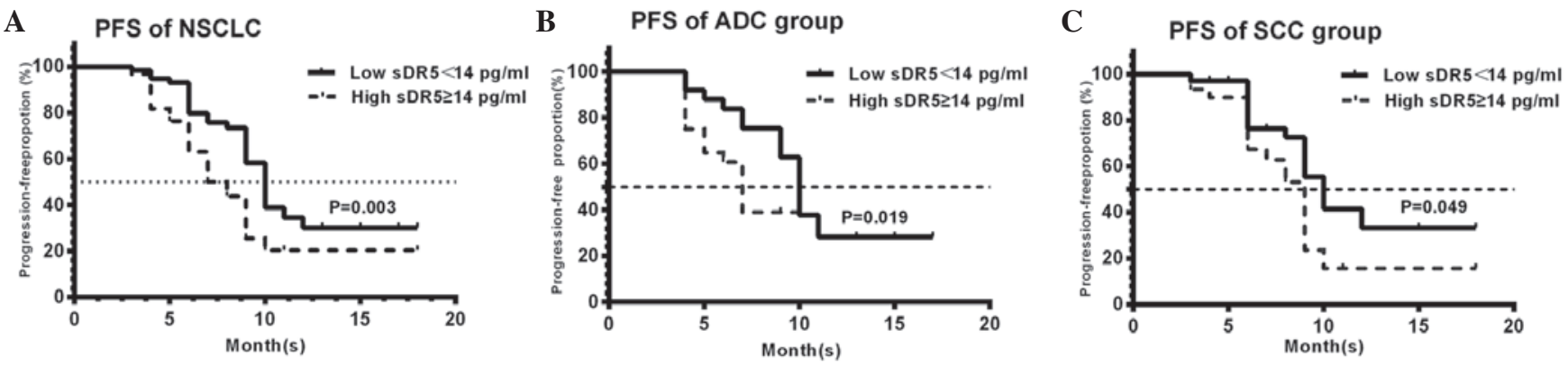

Figure 3. Correlation between pretreatment sDR5 levels and PFS time. The median PFS time was 8.9 months. The cutoff point of $14 \mathrm{pg} / \mathrm{ml}$ was chosen according to receiver operating characteristic analysis. Pretreatment sDR5 levels in patients with sDR5 levels of $<14$ and $\geq 14 \mathrm{pg} / \mathrm{ml}$ were compared in (A) all NSCLC patients $(\mathrm{P}=0.003)$, (B) the ADC subgroup $(\mathrm{P}=0.019)$ and $(\mathrm{C})$ the $\mathrm{SCC}$ subgroup $(\mathrm{P}=0.049)$, using the Kaplan-Meier method. sDR5, soluble death receptor 5; PFS, progression-free survival; NSCLC, non-small cell lung cancer; ADC, adenocarcinoma; SCC, squamous cell carcinoma.

A

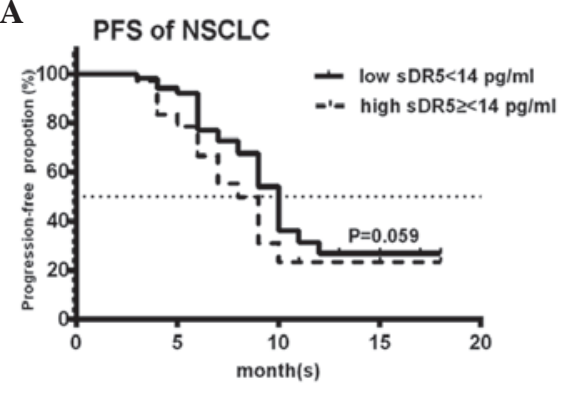

B

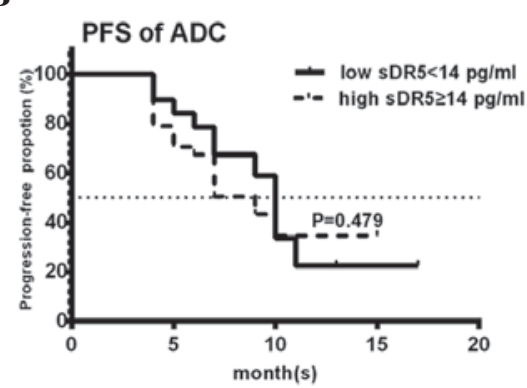

C

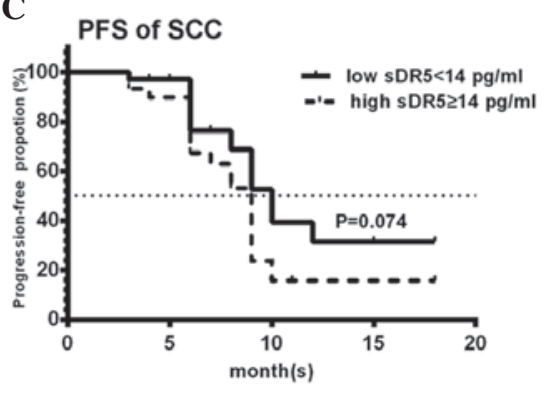

Figure 4. Correlation between post-treatment sDR5 levels and PFS time. The median PFS time was 8.9 months. The cutoff point of $14 \mathrm{pg} / \mathrm{ml}$ was chosen according to receiver operating characteristic analysis. Post-treatment sDR5 levels in patients with sDR5 levels of $<14$ and $\geq 14 \mathrm{pg} / \mathrm{ml}$ were compared in (A) all NSCLC patients $(\mathrm{P}=0.059)$, (B) the ADC subgroup $(\mathrm{P}=0.479)$ and $(\mathrm{C})$ the $\mathrm{SCC}$ subgroup (0.074), using the Kaplan-Meier method. sDR5, soluble death receptor 5; PFS, progression-free survival; NSCLC, non-small cell lung cancer; ADC, adenocarcinoma; SCC, squamous cell carcinoma.

higher than those in patients with $\mathrm{T} 1$ stage tumors $(\mathrm{P}<0.001$; Fig. 2G). Similar results were observed between patients with $\mathrm{T} 1$ and $\mathrm{T} 4$ stage tumors in the ADC $(\mathrm{P}=0.009 ; \mathrm{Fig} .2 \mathrm{H})$ an $\mathrm{SCC}(\mathrm{P}=0.002$; Fig. 2I) subgroups. However, no such correlation was found with $\mathrm{N}$ stage (Fig. 2J-L).

Comparison of sDR5 levels before and after CRT. Analysis of the sDR5 concentrations before and after CRT demonstrated that there were no significant differences between pre- and post-treatment sDR5 concentrations among all NSCLC patients $(\mathrm{P}=0.462)$, the $\mathrm{ADC}$ subgroup $(\mathrm{P}=0.066)$ or the SCC subgroup $(\mathrm{P}=0.052)$, as shown in Table II.

Change in serum DR5 levels according to clinical response after CRT. The treatment response is one of vital indices of the effectiveness of CRT in NSCLC patients. We defined patients with CRs or PRs as responders, while those with stable or progressive disease were considered non-responders, according to RECIST criteria (18). When the patients were grouped according to response to CRT, pretreatment sDR5 levels in the responder group were significantly lower than those in the non-responder group $(\mathrm{P}<0.0001$; Table III). Further analysis in the ADC and SCC subgroups demonstrated the same trend (Table III). However, there was no correlation between the post-treatment sDR5 levels and clinical response (Table IV).
Correlation between SDR5 levels and PFS time. To evaluate the correlation between sDR5 levels and the outcome of patients following CRT, we calculated the PFS time of patients. At the median follow-up of 18 months (range, 3-24 months), the median PFS time was 8.9 months. Patients were then subdivided into two groups according to the sDR5 cutoff value (14 pg/ml), which was calculated by ROC analysis. In the NSCLC group, the median PFS time in patients with pretreatment sDR5 levels of $>14 \mathrm{pg} / \mathrm{ml}$ was 8 months, while that of patients whose pretreatment sDR5 levels were $\leq 14 \mathrm{pg} / \mathrm{ml}$ was 10 months. There was a statistically significant difference in PFS time between the two groups $(\mathrm{P}=0.003$; Fig. 3A). Further analysis of the ADC and SCC subgroups demonstrated the same trend $(\mathrm{P}=0.019$; Fig. $3 \mathrm{~B}$; and $\mathrm{P}=0.049$; Fig. 3C, respectively). That is, high serum sDR5 levels were associated with a lower PFS compared with low sDR5 levels, both in the ADC and SCC subgroups. However, there was no correlation between the post-treatment sDR5 levels and PFS (Fig. 4).

\section{Discussion}

Apoptosis plays a significant role in maintaining body homeostasis. TRAIL/TRAIL-R induced apoptosis is an important regulatory pathway, which serves its potential role as a mediator of tumor immune surveillance (19). DR5 is a 
prominent death domain-containing receptor for TRAIL (20). Our previous study (21) showed that downregulation of DR5 was involved in the apoptosis of the HBV-related hepatoma cell line. To the best of our knowledge, the present study is the first to demonstrate that the serum levels of sDR5 may be a useful biomarker for the diagnosis and prognosis of patients with locally advanced stage III NSCLC.

In several studies, the clinical significance of DR5 expression in human tumors has been determined. Ganten et al (22) showed that DR5 expression was negatively associated with poor clinical outcome in breast cancer patients. Leithner et al (23) demonstrated that nuclear and cytoplasmic DR5 were prognostic factors in patients with NSCLC treated with chemotherapy. Zhuang et al (24) found that decreased DR5 expression was associated with the progression of melanoma. However, all of the above results were obtained by the immunhistochemical analysis of tumor tissues, which is an invasive immunodiagnostic method. In the present study, we used the non-invasive method, ELISA assay, to detect serum soluble DR5 levels and evaluate their diagnostic and prognostic significance in locally advanced NSCLC patients.

The current study found that pretreatment sDR5 serum levels in locally advanced stage III NSCLC patients were higher than the serum sDR5 levels of healthy controls $(\mathrm{P}<0.001)$. According to multiple clinical classification analysis, a significant increase in pretreatment sDR5 serum levels could be observed between IIIB and IIIA stage patients $(\mathrm{P}=0.009)$, and patients with $\mathrm{T} 4$ stage tumors had significantly higher pretreatment sDR5 levels compared with those with $\mathrm{T} 1$ stage tumors $(\mathrm{P}<0.001)$. Furthermore, patients with a tumor burden of $>3 \mathrm{~cm}$ had higher pretreatment sDR5 concentrations compared with those with tumor burdens of $\leq 3 \mathrm{~cm}$. The results showed that pretreatment sDR5 serum concentrations may be a usefully adjunctive factor in the diagnosis of locally advanced stage III NSCLC patients.

Further analysis found that when patients were divided according to therapeutic response (responders versus non-responders), the pretreatment sDR5 levels were significantly lower in responders compared with non-responders $(\mathrm{P}=0.007)$. Therefore, CRT was more effective in patients with lower pretreatment sDR5 levels than in those with higher pretreatment sDR5 levels. The results indicated that pretreatment serum sDR5 levels may aid in the development of more powerful strategies to improve the treatment efficacy for locally advanced stage III NSCLC patients.

To investigate the correlation between the sDR5 levels and the outcome of the NSCLC patients, PFS survival analysis was performed. It was found that high sDR5 serum levels were associated with a shorter PFS time compared with low sDR5 levels in NSCLC patients; patients whose pretreatment sDR5 levels were $\leq 14 \mathrm{pg} / \mathrm{ml}$ (cutoff value, $14 \mathrm{pg} / \mathrm{ml}$ ) had an improved disease outcome compared with patients whose pretreatment sDR5 levels were $>14 \mathrm{pg} / \mathrm{ml}$. These results indicated that serum sDR5 levels may be a useful prognostic biomarker for patients with locally advanced stage III NSCLC.

At present, the cellular origin of the increased serum sDR5 levels observed in the present study is unknown. Although Yildiz et al detected the expression of serum sDR5 levels in metastatic colorectal cancer, the authors did not investigate the generation of serum sDR5 (9). We propose that another important death receptor, serum sFas, may originate from the tumor tissues themselves, as a correlation between sFas/CD95 serum concentration and the patient's stage of disease has been observed (25). In the present study, it was also found that serum sDR5 levels correlated with the patient's stage of disease and disease progression. Therefore, according to the above evidence, we hypothesize that sDR5 may be generated by the lung cancer tissue itself.

However, no correlation was identified between the post-sDR5 level and the treatment response or the PFS time in the present study. These results may be due to the fact that post-treatment sDR5 levels were affected by six weeks of CRT. Post-treatment sDR5 levels had no prognostic significance in locally advanced stage III NSCLC patients

In conclusion, pretreatment sDR5 serum concentration s may be a usefully adjunctive diagnostic index for locally advanced stage III NSCLC patients. Notably, pretreatment sDR5 levels in the patient's serum may be a predictive and prognostic biomarker for the effectiveness of CRT in locally advanced stage III NSCLC patients.

\section{Acknowledgements}

The authors thank Dr Jan Clay and Dr Suzanne Bither for manuscript assistance. This study was supported by grants from the Natural Science Foundation of Shandong Province (grant no. ZR2011HQ010), the National Natural Science Foundation of China (grant nos. 81272501, 30901712 and 81000731) and the Fund for Excellent Young and Middle-Aged Scientists of Shandong Province (grant no. BS2010YY045).

\section{References}

1. Spierings DC, de Vries EG, Timens W, Groen HJ, Boezen HM and de Jong S: Expression of TRAIL and TRAIL death receptors in stage III non-small cell lung cancer tumors. Clin Cancer Res 9: 3397-3405, 2003.

2. Ettinger DS, Akerley W, Borghaei H, et al: Non-small cell lung cancer, version 2.2013. J Natl Compr Canc Netw 11: 645-653, 2013.

3. Chute JP, Chen T, Feigal E, Simon R and Johnson BE: Twenty years of phase III trails for patients with extensive-stage small-cell lung cancer: perceptible progress. J Clin Oncol 17: 1794-1801, 1999.

4. Machtay M, Bae K, Movsas B, et al: Higher biologically effective dose of radiotherapy is associated with improved outcomes for locally advanced non-small cell lung carcinoma treated with chemoradiation: an analysis of the Radiation Therapy Oncology Group. Int J Radiat Onclo Biol Phys 82: 425-434, 2012.

5. Aupérin A, Le Péchoux C, Rolland E, et al: Meta-analysis of concomitant versus sequential radiochemotherapy in locally advanced non-small-cell lung cancer. J Clin Oncol 28: 2181-2191, 2010.

6. Igney FH and Krammer PH: Death and anti-death: tumour resistance to apoptosis. Nat Rev Cancer 2: 277-288, 2002.

7. Malhi $\mathrm{H}$ and Gores GJ. TRAIL resistance results in cancer progression: a TRAIL to perdition? Oncogene 25: 7333-7335, 2006.

8. Baader E, Toloczko A, Fuchs U, et al: Tumornecrosis factor-related apoptosis-inducing ligand-mediated proliferation of tumor cells with receptor-proximal apoptosis defects. Cancer Res 65: 7888-7895, 2005

9. Yildiz R, Benekli M, Buyukberber S, et al: The effect of bevacizumab on serum soluble FAS/FASL and TRAIL and its receptors (DR4 and DR5) in metastatic colorectal cancer. J Cancer Res Clin Oncol 136: 1471-1476, 2010.

10. Yang H, Li H, Wang Z, Gao J and Guo Y: Is urinary soluble fas an independent predictor of non-muscle-invasive bladder cancer? A prospective chart study. Urol Int 91: 456-461, 2013.

11. van Dijk M, Halpin-McCormick A, Sessler T, Samali A and Szegezdi E: Resistance to TRAIL in non-transformed cells is due to multiple redundant pathways. Cell Death Dis 4: e702, 2013. 
12. Wiley SR, Schooley K, Smolak PJ, et al: Identification and characterization of a new member of the TNF family that induces apoptosis. Immunity 3: 673-682, 1995.

13. LeBlanc HN and Ashkenazi A: Apo2L/TRAIL and its death and decoy receptors. Cell Death Differ 10: 66-75, 2003.

14. Truneh A, Sharma S, Silverman C, et al: Temperature-sensitive differential affinity of TRAIL for its receptors. DR5 is the highest affinity receptor. J Biol Chem 275: 2319-2325, 2000.

15. Du J, Wang L, Han J, Gao L, Ma C and Liang X: Serum soluble death receptor 5 concentration in patients with chronic hepatitis $\mathrm{B}$ is associated with liver damage and viral antigen level. Clin Biochem 45: 845-847, 2012.

16. Edge SB, Byrd DR, Compton CC, et al (eds): Thorax. In: AJCC Cancer Staging Manual. 7th edition. Springer, New York, NY, pp299-323, 2010.

17. Goldstraw P, Crowley J, Chansky K, et al: The IASLC Lung Cancer Staging Project: proposals for the revision of the TNM stage groupings in the forthcoming (seventh) edition of the TNM classification of malignant tumors. J Thorac Oncol 2: 706-714, 2007.

18. Therasse P, Arbuck SG, Eisenhauer EA, et al: New guidelines to evaluate the response to treatment in solid tumors. European Organization for Research and Treatment of Cancer, National Cancer Institute of the United States, National Cancer Institute of Canada. J Natl Cancer Inst 92: 205-216, 2000.

19. Takeda K, Hayakawa Y, Smyth MJ, et al: Involvement of tumor necrosis factor-related apoptosis-inducing ligand in surveillance of tumor metastasis by liver natural killer cells. Nat Med 7: 94-100, 2001.
20. Kelley RF, Totpal K, Lindstrom SH, et al: Receptor-selective mutants of apoptosis-inducing ligand $2 /$ tumor necrosis factor-related apoptosis-inducing ligand reveal a greater contribution of death receptor (DR) 5 than DR4 to apoptosis signaling. J Biol Chem 280: 2205-2212, 2005.

21. Du J, Liang X, Liu Y, et al: Hepatitis B virus core protein inhibits TRAIL-induced apoptosis of hepatocytes by blocking DR5 expression. Cell Death Differ 16: 219-229, 2009.

22. Ganten TM, Sykora J, Koschny R, et al: Prognostic significance of tumour necrosis factor-related apoptosis-inducing ligand(TRAIL) receptor expression in patients with breast cancer. J Mol Med (Berl) 87: 995-1007, 2009.

23. Leithner K, Stacher E, Wurm R, et al: Nuclear and cytoplasmic death receptor 5 as prognostic factors in patients with non-small cell lung cancer treated with chemotherapy. Lung Cancer 65: 98-104, 2009.

24. Zhuang L, Lee CS, Scolyer RA, et al: Progression in melanoma is associated with decreased expression of death receptors for tumor necrosis factor-related apoptosis-inducing ligand. Hum Pathol 37: 1286-1294, 2006.

25. Ugurel S, Rappl G, Tilgen W, Reinhold U: Increased soluble CD95 (sFas/CD95) serum level correlates with poor prognosis in melanoma patients. Clin Cancer Res 7: 1282-1286, 2001. 